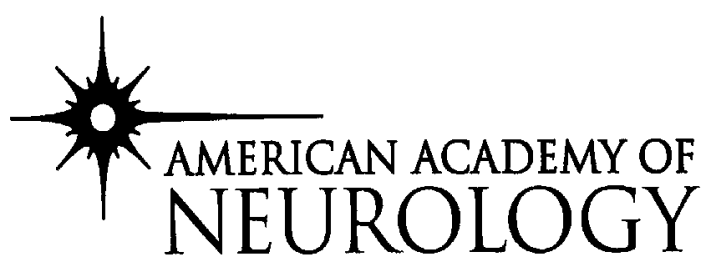

\title{
REASSESSMENT: VAGUS NERVE STIMULATION FOR EPILEPSY
}

\author{
A Report of the Therapeutics and Technology Assessment Subcommittee \\ of the American Academy of Neurology
}

Robert S. Fisher, MD, PhD; and Adrian Handforth, MD

A July 1997 assessment of the American Academy of Neurology (AAN) Therapeutics and Technology Subcommittee reviewed vagus nerve stimulation (VNS) for epilepsy, and concluded that it was promising, but not yet established. ${ }^{1}$ Subsequent to that review, a second multicenter, randomized, controlled clinical trial has shown safety and efficacy of VNS for treatment of intractable partial seizures. Given the importance of this novel therapy for epilepsy, and the new information provided by a second major study, the Therapeutics and Technology Subcommittee requested an update on VNS. Use of VNS in epilepsy has recently been reviewed. ${ }^{2-4}$

VNS uses intermittent stimulation of the left vagus nerve in the neck to reduce the frequency and intensity of seizures. Mechanism of action of VNS remains uncertain, but stimulation does not induce grossly visible alterations in the human EEG. ${ }^{5}$ Recent studies suggest that metabolic activation of certain thalamic, brainstem, and limbic structures may be important in mediating the effect of VNS. ${ }^{6,7}$ Depletion of norepinephrine in the locus coeruleus attenuates the antiseizure affect of VNS. ${ }^{8}$

After open-label studies, ${ }^{9,10}$ sponsors of VNS engaged in a multicenter randomized study, named E03, ${ }^{11}$ details of which were reviewed in the previous assessment. ${ }^{1}$ Results of the trial were positive, and the technology was considered promising, but the number of patients receiving VNS was insufficient to achieve Food and Drug Administration approval. Therefore, a second randomized, controlled, multicenter clinical trial, called E05, was undertaken. $^{12}$

Update on controlled studies. The E05 study ${ }^{12}$ of VNS evaluated 254 patients, ages 13 to 60 years, with intractable partial seizures. To be eligible, subjects had to have at least six complex partial, visible partial motor, or secondarily generalized seizures in the month before entry, and to be free from other complicating neurologic, psychiatric, or medical conditions. Individuals with prior VNS were excluded. After a 12- to 16-week baseline, the vagus nerve stimulator electrode was implanted around the left vagus nerve and connected subcutaneously to the subclavicular stimulator device. Two weeks after implantation, patients were randomly assigned to high- or lowstimulation groups. Current was increased over 2 weeks, and maintained for 3 months of treatment. The highstimulation group received stimulation with $500-\mu \mathrm{sec}$ pulses at 30 pulses per second, on for 30 seconds and off for 5 minutes. Current was increased as tolerated over the next 16 weeks to a maximum of $3.5 \mathrm{~mA}$. Patients receiving low stimulation as an active control received $130-\mu$ sec pulses at one per second, on for 30 seconds and off for 3 hours, with $\mathrm{mA}$ set to the point of patient perception. All patients were told that they could activate the stimulator with a hand-held magnet to produce a 30 -second stimulation train at the start of a perceived seizure; however, only patients in the high-stimulation group actually received magnet-induced stimulation.

The 94 patients receiving high stimulation showed an average reduction in seizure frequency compared to baseline of $28 \%$, versus $15 \%$ reduction in the 102 patients receiving low stimulation $(p=0.04)$. No significant difference was found in the number of people who sustained a $50 \%$ reduction in seizure frequency between the two groups, but a difference was seen for those experiencing a 75\% reduction in favor of high stimulation. Global

From the American Academy of Neurology, St. Paul, MN.

Dr. Fisher is supported by the Sandra Solheim Aiken Fund for Epilepsy, The Marjorie Newsome Trust, and the Women's Board of the Barrow Neurological Association.

Approved by the AAN Therapeutics and Technology Assessment Subcommittee April 21, 1999. Approved by the Practice Committee April 22, 1999. Approved by the Executive Board of the AAN June 19, 1999.

Received March 3, 1999. Accepted in final form April 16, 1999

Address correspondence and reprint requests to the Therapeutics and Technology Assessment Subcommittee, American Academy of Neurology, 1080 Montreal Ave., St. Paul, MN 55116. 
evaluation scores by the patients (a subjective ranking of whether they overall are better or worse and the degree of change) were higher for the group given higher levels of stimulation.

A total of 310 patients completed the E03 and E05 double-blinded trials. Mean decline of seizure frequency overall was about 25 to $30 \%$ compared to baseline. Clinical experience has shown that improvement in seizures is maintained, or may even increase over time, but these data are based on uncontrolled observations. ${ }^{13,14}$

Side effects in the E05 were similar to those of the E03 study, consisting primarily of hoarseness and occasional shortness of breath. One patient in the low-stimulation group withdrew owing to a variety of symptoms during the stimulation ramp-up phase. A total of 194 of the 196 entered patients (99\%) completed the study. Hoarseness or throat discomfort occurred in about one-third of patients using VNS. Most patients tolerated the hoarseness during stimulation, especially when stimulation current was initiated slowly. No changes in physiologic markers for gastric, cardiac, or pulmonary function were observed, and no patient had serious side effects. One patient in the highstimulation group had respiratory problems and withdrew, but problems persisted and did not worsen upon rechallenge. A recent study ${ }^{15}$ reported two children who had swallowing difficulties and aspiration documented with a barium swallowing study during stimulation of the vagus nerve.

Because deaths occurred in the E05 clinical trial, analysis was made of the sudden unexplained death in epilepsy (SUDEP) rate compared with the expected baseline rate. ${ }^{16}$ A group of 791 patients with implanted vagus nerve stimulators were followed for an average of approximately 2 years each. Among this group, 15 deaths occurred during stimulation, of which six were considered to represent SUDEP. The incidence of definite/probable SUDEP was 4.5 per 1,000 person-years, and the standardized mortality ratio was 5.3 times the baseline population rate. These mortality and unexplained death rates are comparable to those seen in recent studies of new antiepileptic medications, performed on a population of patients with severe seizures. No increased risk of mortality could be attributed to VNS.

VNS has been best studied in partial seizures in adults. The treatment was evaluated in five patients with drugresistant symptomatic generalized seizures. ${ }^{17}$ The median seizure rate was reduced by $41 \%$ compared to baseline. Note should be made that the above trial ${ }^{17}$ did not address the issue of VNS efficacy in primary generalized seizures, and was too small to allow conclusions about efficacy for generalized seizures of any type. Controlled trials of VNS use in patients with generalized seizures were recommended.

Data are being gathered about use of VNS in the pediatric population. Outcome has been summarized for 19 children using VNS as treatment for their intractable seizures. ${ }^{18}$ In this open-label trial, 53\% had at least a 50\% reduction in seizures. Among six children with Lennox-Gastaut syndrome, five sustained at least a $90 \%$ reduction of seizures. Sixteen children treated with VNS, ages 4 to 19 years, experienced a $38 \%$ responder rate. ${ }^{19}$ Adverse events included hoarseness, neck pain, drooling, fatigue, and aspiration during drinking. Children tolerate VNS, but may experience technical complications requiring repair or replacement of the device. ${ }^{20}$ The available data support the use of the vagus nerve stimulator in patients 13 years and older. Insufficient data are available at this time to permit definitive statements regarding the relative risks and benefits of this technique in children younger than 13 years of age.

In the opinion of the committee, VNS is indicated for adults and adolescents over 12 years of age with medically intractable partial seizures who are not candidates for potentially curative surgical resections, such as lesionectomies or mesial temporal lobectomies. The Committee believes that patients should undergo a thorough evaluation of their epilepsy to rule out nonepileptic conditions or treatable symptomatic epilepsies before implantation of a vagus nerve stimulator. When MRIs are indicated, they are preferably obtained before implantation, because data are insufficient to allow conclusions on safety of MRI after implantation of a VNS. Insufficient data are available to identify which patients are likely to benefit from VNS. Because VNS rarely causes complete seizure remission, and is moderately invasive and expensive, use of VNS is more appropriate in individuals unable to tolerate or benefit from antiepileptic drugs (AEDs), and for whom a partial reduction in seizure frequency will significantly improve their quality of life.

Conclusion. The degree of improvement in seizure control from VNS remains comparable to that of new AEDs, ${ }^{21}$ but is lower than that of mesial temporal lobectomy in suitable surgical resection candidates. ${ }^{22}$ Some patients appear willing to undergo implantation of a vagus nerve stimulator to avoid the usual undesirable effects of antiepileptic medication. As with AED studies, the VNS population studied in pivotal trials was refractory to standard therapy, and may therefore present a particular challenge to new therapies. Efficacy of VNS in less severely affected populations remains to be evaluated. Nevertheless, sufficient evidence exists to rank VNS for epilepsy as effective and safe, based on a preponderance of Class I evidence. 
Note. At the time of this writing, such efficacy was recognized by the US Food and Drug Administration, Medicare, the central advisory board of Blue Cross-Blue Shield, and several other third party payors.

Disclaimer. This statement is provided as an educational service of the American Academy of Neurology. It is based on an assessment of current scientific and clinical information. It is not intended to include all possible proper methods of care for a particular neurologic problem or all legitimate criteria for choosing to use a specific procedure. Neither is it intended to exclude any reasonable alternative methodologies. The American Academy of Neurology recognizes that specific patients care decisions are the prerogative of the patient and the physician caring for the patient, based on all of the circumstances involved.

\section{Acknowledgments}

The authors thank the members of the American Academy of Neurology Therapeutics and Technology Assessment Committee and the many individual members of the American Academy of Neurology who provided review and comment on manuscript.

\section{Appendix 1}

American Academy of Neurology Therapeutics and Technology Assessment Subcommittee members: John Ferguson, MD (chair); Elliot Mark Frohman, MD, PhD; Robert Goldman, MD; Douglas Goodin, MD; Philip B. Gorelick, MD, MPH; Chung Hsu, MD, PhD; Andres Kanner, MD (facilitator); Anne Marini, MD; E. Steven Roach, MD; and Edward Westbrook, MD.

\section{Appendix 2 \\ Definitions}

Safe: A judgment of the acceptability or risk in a specified situation, e.g., for agiven medical problem, by a provider with specified training, at a specified type of facility

Effective: Producing a desired effect under conditions of actual use.

Established: Accepted as appropriate by the practicing medical community for the given indication in the specified patient population.

Possibly useful: Given current knowledge, this technology appears to be appropriate for the given indication in the specified patient population. If more experience and long-term follow-up are accumulated, this interim rating may change.

Investigational: Evidence insufficient to determine appropriateness, warrants further study. Use of this technology for given indication in the specified patient population should be confined largely to research protocols.

Doubtful: Given current knowledge, this technology appears to be inappropriate for the given indication in the specified patient population. If more experience and long-term follow-up are accumulated, this interim rating may change.

Unacceptable: Regarded by the practicing medical community as inappropriate for the given indication in the specified patient population.

\section{Quality of evidence ratings for therapeutic modalites}

Class I. Evidence provided by one or more well-designed randomized, controlled clinical trials.

Class II. Evidence provided by one or more well-designed clinical studies such as case control, cohort studies, etc. Class III. Evidence provided by expert opinion, nonrandomized historical controls, or reports of one or more.

\section{Strength of recommendations}

Type A. Strong positive recommendations, based on Class I evidence, or overwhelming Class II evidence when circumstances preclude randomized clinical trials.

Type B. Positive recommendation, based on Class II evidence.

Type C. Positive recommendation, based on strong consensus of Class III evidence.

Type D. Negative recommendation, based on inconclusive or conflicting Class II evidence.

Type E. Negative recommendation, based on evidence of ineffectiveness or lack of efficacy, based on Class II or Class I evidence.

\section{Disclosure}

Both authors have received speaker's bureau support from Cyberonics, the company sponsoring the vagus nerve stimulator for epilepsy. Dr. Handforth has received research support from Cyberonics and also served as the lead author in the E05 study of VNS. Neither author holds an equity position in Cyberonics. 


\section{References}

1. Fisher RS, Krauss GL, Ramsay E, Laxer K, Gates J. Assessment: vagus nerve stimulation for epilepsy. Neurology 1997;49:293-297.

2. Schachter SC, Saper CB. Vagus nerve stimulation. Epilepsia 1998;39:677-686.

3. Ben-Menachem E. Modern management of epilepsy: vagus nerve stimulation. Baillieres Clin Neurol 19965:841-848.

4. McLachlan RS. Vagus nerve stimulation for intractable epilepsy: a review. J Clin Neurophysiol 1997;14:358-368.

5. Hammond EJ, Uthman BM, Reid SA, Wilder BJ. Electrophysiological studies of cervical vagus nerve stimulation in humans: I. EEG effects. Epilepsia 1992;33:1013-1020.

6. Henry TR, Bakay RA, Votaw JR, et al. Brain blood flow alterations induced by therapeutic vagus nerve stimulation in partial epilepsy: I. Acute effects at high and low levels of stimulation. Epilepsia 1998;39:983990.

7. Ko D, Heck C, Grafton S, et al. Vagus nerve stimulation activates central nervous system structures in epileptic patients during PET $\mathrm{H}_{2}\left({ }^{15}\right)$ O blood flow imaging. Neurosurgery 1996;39:426-430.

8. Krahl SE, Clark KB, Smith DC, Browning RA. Locus coeruleus lesions suppress the seizure-attenuating effects of vagus nerve stimulation. Epilepsia 1998;39:709-714.

9. Penry JK, Dean JC, Spudis EV, Bell WO, Terry R. Prevention of partial seizures by intermittent vagal nerve stimulation in humans. Epilepsia 1989;30:706.

10. Uthman BM, Wilder BJ, Penry JK, et al. Treatment of epilepsy by stimulation of the vagus nerve. Neurology 1993;43:1338-1345.

11. Ben-Menachem E, Mañon-Espaillat R, Ristanovic R, et al. Vagus nerve stimulation for treatment of partial seizures: 1. A controlled study of effect on seizures. Epilepsia 1994;35:616-626.

12. Handforth A, DeGiorgio CM, Schachter SC, et al. Vagus nerve stimulation therapy for partial-onset seizures: a randomized active-control trial. Neurology 1998;51:48-55.

13. George R, Salinsky M, Kuzniecky R, et al. Vagus nerve stimulation for treatment of partial seizures: 2. Long-term follow-up on first 67 patients exiting a controlled study. Epilepsia 1994;35:637-643.

14. Salinsky MC, Uthman BM, Ristanovic RK, Wernicke JF, Tarver WB, and the Vagus Nerve Stimulation Study Group. Vagus nerve stimulation for the treatment of medically intractable seizures: results of a 1-year open-extension trial. Arch Neurol 1996;53:1176-1180.

15. Lundgren J, Ekberg O, Olsson R. Aspiration: a potential complication to vagus nerve stimulation. Epilepsia 1998;39:998-1000.

16. Annegers JF, Coan SP, Hauser WA, Leestma J, Duffell W, Tarver B. Epilepsy, vagal nerve stimulation by the NCP system, mortality, and sudden, unexpected, unexplained death. Epilepsia 1998;39:206-212.

17. Labar D, Nikolov B, Tarver B, Fraser R. Vagus nerve stimulation for symptomatic generalized epilepsy: a pilot study. Epilepsia 1998;39:201-205.

18. Hornig GW, Murphy JV, Schallert G, Tilton C. Left vagus nerve stimulation in children with refractory epilepsy: an update. South Med J 1997;90:484-488.

19. Lundgren J, Amark P, Blennow G, Stromblad LG, Wallstedt L. Vagus nerve stimulation in 16 children with refractory epilepsy. Epilepsia 1998;39:809-813.

20. Murphy JV, Hornig GW, Schallert GS, Tilton CL. Adverse events in children receiving intermittent left vagal nerve stimulation. Pediatr Neurol 1998;19:42-44.

21. Levy RH, Mattson RH, Meldrum BS, eds. Antiepileptic drugs, fourth edition. New York: Raven Press, 1995;1-1120.

22. Engel J Jr. Surgery for seizures. N Engl J Med 1996;334:647-652. 


\title{
Neurology
}

\author{
Reassessment: Vagus nerve stimulation for epilepsy [RETIRED]: A Report of the \\ Therapeutics and Technology Assessment Subcommittee of the American Academy of \\ Neurology. \\ Robert S. Fisher and Adrian Handforth \\ Neurology 1999;53;666 \\ DOI 10.1212/WNL.53.4.666
}

\section{This information is current as of September 1,1999}

Updated Information \&

Services

Citations

Permissions \& Licensing

Reprints including high resolution figures, can be found at: http://n.neurology.org/content/53/4/666.full

This article has been cited by 8 HighWire-hosted articles: http://n.neurology.org/content/53/4/666.full\#\#otherarticles

Information about reproducing this article in parts (figures,tables) or in its entirety can be found online at:

http://www.neurology.org/about/about_the_journal\#permissions

Information about ordering reprints can be found online:

http://n.neurology.org/subscribers/advertise

Neurology ${ }^{\circledR}$ is the official journal of the American Academy of Neurology. Published continuously since 1951, it is now a weekly with 48 issues per year. Copyright . All rights reserved. Print ISSN: 0028-3878. Online ISSN:

$1526-632 X$.

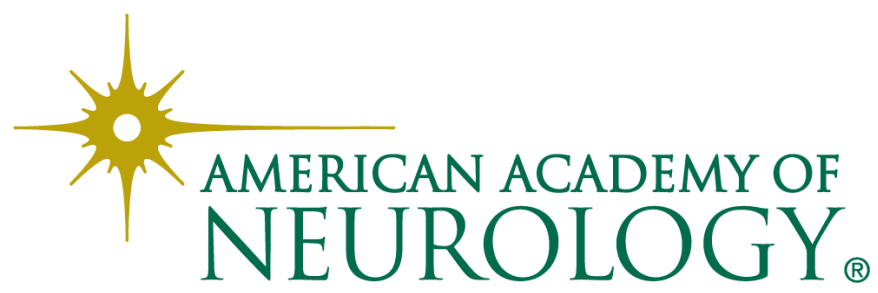

